\title{
Continuum beliefs in the stigma process regarding persons with schizophrenia and depression: results of path analyses
}

\author{
Anna C Makowski ${ }^{\text {Corresp., }}{ }^{1}$ ， Eva E Mnich ${ }^{1}{ }^{\text {, }}$ Matthias C Angermeyer ${ }^{2,3}$, Olaf von dem Knesebeck ${ }^{1}$ \\ 1 Department of Medical Sociology, University Medical Center Hamburg-Eppendorf, Hamburg, Germany \\ 2 Center for Public Mental Health, Gösing am Wagram, Austria \\ 3 Department of Clinical and Molecular Medicine and Public Health, University of Cagliari, Cagliari, Italy \\ Corresponding Author: Anna C Makowski \\ Email address: a.makowski@uke.de
}

Background Individuals with mental illness often experience stigmatization and encounter stereotypes such as being dangerous or unpredictable. To further improve measures against psychiatric stigma, it is of importance to understand its components. In this study, we attend to the step of separation between "us" and "them" in the stigma process as conceptualized by Link and Phelan. In using the belief in continuity of mental illness symptoms as a proxy for separation, we explore its associations with stereotypes, emotional responses and desire for social distance in the stigma process.

Methods Analyses are based on a representative survey in Germany. Vignettes with symptoms suggestive of schizophrenia $(\mathrm{N}=1,338)$ or depression $(\mathrm{N}=1,316)$ were presented to the respondents, followed by questions on continuum belief, stereotypes, emotional reactions and desire for social distance. To examine the relationship between these items, path models were computed.

Results Respondents who endorsed the continuum belief tended to show greater prosocial reactions (schizophrenia: $0.07 ; p<0.001$, depression: $0.09 ; p<0.001$ ) and less desire for social distance (schizophrenia: -0.13 ; $p<0.001$, depression: $-0.14 ; p<0.001$ ) toward a person with mental illness. In both cases, agreement with the stereotypes of unpredictability and dangerousness was positively associated with feelings of anger and fear as well as desire for social distance. There were no statistically significant relations between stereotypes and continuum beliefs.

Discussion Assumptions regarding continuum beliefs in the stigma process were only partially confirmed. However, there were associations of continuum beliefs with less stigmatizing attitudes toward persons affected by either schizophrenia or depression. Including information on continuity of symptoms, and thus oppose perceived separation, could prove helpful in future anti-stigma campaigns. 
Continuum beliefs in the stigma process regarding persons with schizophrenia and depression: results of path analyses

Anna C. Makowski ${ }^{*}$, Eva E. Mnich ${ }^{1}$, Matthias C. Angermeyer ${ }^{2}$, Olaf von dem Knesebeck ${ }^{1}$

${ }^{1}$ Department of Medical Sociology, University Medical Center Hamburg-Eppendorf

${ }^{2}$ Center for Public Mental Health, Gösing am Wagram, Austria and Department of Clinical and Molecular Medicine and Public Health, University of Cagliari, Italy

${ }^{*}$ Corresponding author:

Anna Christin Makowski, M.Sc.

Department of Medical Sociology

University Medical Center Hamburg-Eppendorf

Martinistrasse 52

20246 Hamburg, Germany

Phone: +49 (0) 40741054415

Fax: +49 (0) 40741054934

a.makowski@uke.de 


\section{Introduction}

2 Despite a progress in evidence-based treatments and increasing public knowledge about mental

3 disorders, persons with mental illness still report direct experience of stigma and discrimination

4 [1]. Internalized stigma is negatively associated with lower self-esteem, empowerment and

5 treatment adherence [2] and individuals with mental health problems still encounter stereotypes.

6 Negative emotional reactions as well as desire for social distance toward persons affected have

7 even increased over the last decades [3]. Previous research in Germany on the public stereotype

8 of schizophrenia has found the ascription of being unpredictable the most prevalent, followed by

9 the perception of dangerousness, while blaming the person for the illness was the least common.

While dangerousness and being unpredictable were strong predictors of desire for social distance, blaming the person was associated with the acceptance of structural discrimination [4]. Similar results on the prevalence of stereotypes have also been obtained by a more recent study evaluating the effects of documentary film on stigmatization [5]. The concern about social rejection and insufficient mental health literacy has led to various public campaigns such as "beyond blue" in Australia [6], "Time to Change" in Great Britain [7], the German campaigns "Nuremberg Alliance against Depression" [8] and "psychenet - Hamburg Network for Mental Health" [9] or "Schizophrenia has many faces" in Austria [10]. The evaluation of the different campaigns came to inconsistent results due to different outcome parameters and indicators used. Some reported improvement in intended behavior but not for knowledge and attitudes [7], others showed only minor changes in attitudes [9] or even found an increase in desire for social distance over the course of time [10].

In order to further improve strategies to reduce stigma, it is of importance to understand its components and associated factors. Link and Phelan [11] have conceptualized the stigma process model consisting of several distinct, but interrelated steps. In this conceptualization, stigma exists when the following components converge: 1) distinguishing and labeling human differences, which is a natural selection as soon as it comes to differences that matter socially. 2) Dominant cultural beliefs link these labeled differences to undesirable characteristics (stereotypes). 3) Labeled persons are placed in distinct categories to separate "us" from "them". 4) Labeled persons experience status loss and discrimination. Additionally, Link et al. [12] incorporated emotional responses into this process, which are critical to understanding the 
31 behavior of stigmatizer and recipients of stigmatizing reactions. Labeling, stereotyping and separation are likely to be associated with emotions such as anger, anxiety and pity. These emotional responses may shape subsequent behavior toward the stigmatized person. This sequence of emotional response and performed conduct has also been postulated by Weiner [13] in attribution theory.

A lot of research has attended to the stigma process. However, the focus was mostly on single components or the interaction of a few steps in the stigma process. Link et al. [12] have reviewed empirical articles published on the stigma of mental illness between 1995 and 2003 and took note which concepts had been covered. Most articles were published on stereotyping, followed by status loss/discrimination, emotional reactions and cognitive separation (explained by the authors as fundamental differences between "us" and "them" implied by social labels). In a study by Angermeyer and Matschinger [14], labeling a person in a vignette as mentally ill (in this case schizophrenia) was associated with an increased likelihood to be tied to stereotypes such as dangerous or unpredictable, which led to greater desire for social distance. Moreover, the authors found that labeling someone as mentally ill and perceiving this person as dangerous was closely associated with feelings of fear and anger [15]. Martin et al. [16] also showed that respondents who labeled a vignette as mental illness expressed greater desire to socially distance themselves. For the case of schizophrenia, a review by Read et al. [17] found that diagnostic labeling by the public was associated with greater desire for social distance as well as fearful reactions. This is also corroborated by Jorm and Griffiths [18], who found associations between a biomedical conceptualization of mental illness and a belief in dangerousness for schizophrenia. Another central step in the stigma process, the separation between "us" and "them" has only scarcely been researched. Only few studies were found which explicitly dealt with a continuum concept of mental (ill-) health. This concept implicates that mental health and illness can be located on a continuum rather than a clear, dichotomized separation. Regarding the public's agreement or disagreement to continuity of mental illness, Schomerus et al. [19] found that belief in a continuum was related to decreased feelings of fear, but greater feelings of anger. In all disorders under study (depression, alcohol dependence, schizophrenia), continuum beliefs were significantly associated with greater pro-social reactions and lower desire for social distance. Similar results were published by Angermeyer et al. [20], who also found associations between continuum beliefs and positive emotional reactions as well as decreased desire for social distance 
62 in the case of depression and schizophrenia. Wiesjahn et al. [21] examined the association

63 between continuum belief and stigmatization using the Continuum Beliefs Questionnaire. Higher

64 levels of continuum beliefs were associated with lower levels of stereotypes. However, there

65 were no associations with desire for social distance.

66 Against this background, we set out to explore the relationship of four consecutive components

67 of the stigma process, with a particular focus on continuum beliefs. The aim of this study is to

68 incorporate the belief in continuity of mental illness symptoms into the stigma process model

$69[11,12]$ and to estimate the associations using a path modeling approach. We assume the belief

70 in continuity of symptoms to be a proxy for the step of separation in the stigma process.

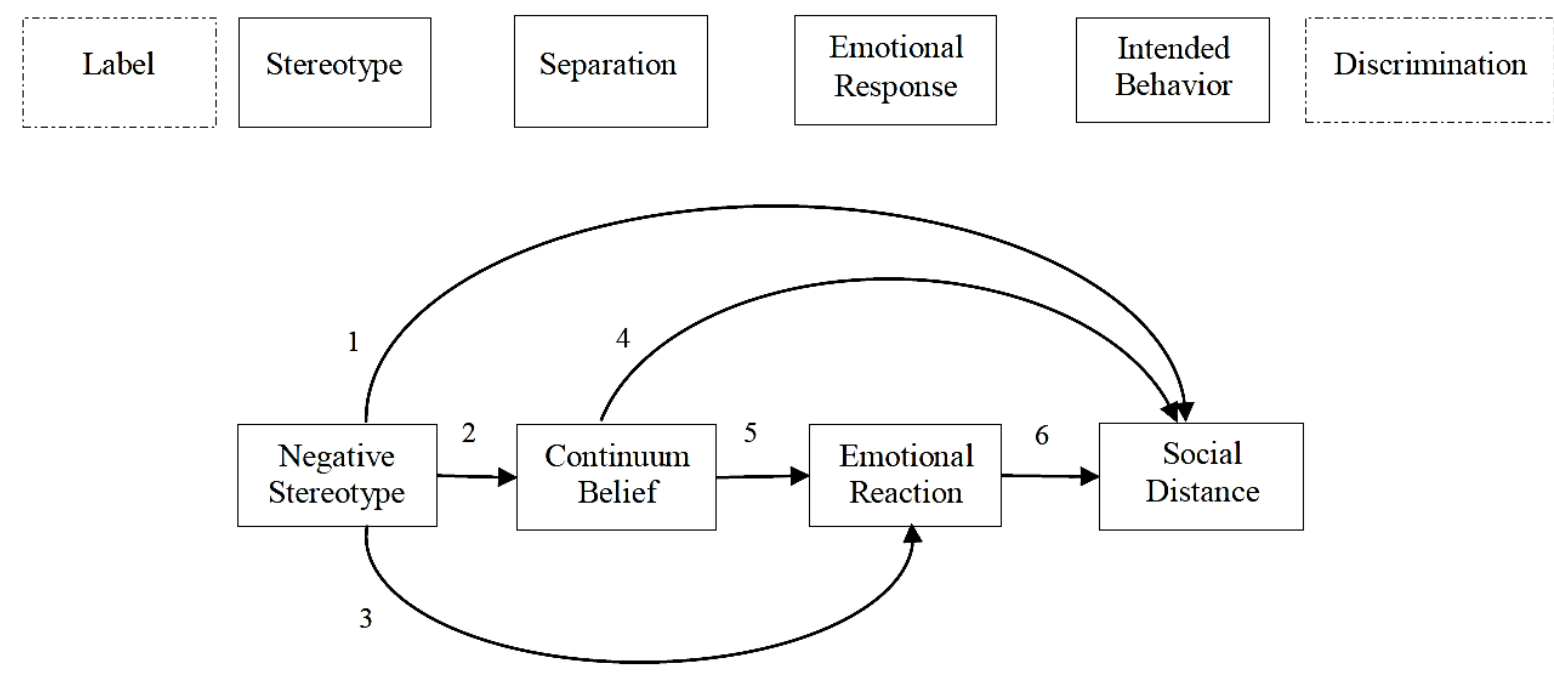

Figure 1 Theoretical model based on the stigma process as postulated by Link and Phelan [11, 12]

Figure 1 displays the theoretical considerations based on the stigma process model. We assume the following:

(1) Positive association between stereotype and desire for social distance

(2) Negative association between stereotype and continuum belief

(3) Positive association between stereotype and feelings of anger and fear; negative association between stereotype and positive emotional reactions

(4) Negative association between continuum belief and desire for social distance 
(5) Positive association between continuum belief and positive emotional reactions, negative association between continuum belief and feelings of anger and fear

(6) Negative association between positive emotional reaction and desire for social distance, positive association between feelings of anger and fear and desire for social distance

\section{Methods}

\section{Study Design and Sample}

Analyses were based on a telephone survey (CATI - computer assisted telephone interview), which had been conducted in the German cities Hamburg and Munich in the spring of 2014. The survey was part of psychenet - Hamburg network for mental health, a joint project in the metropolitan area of Hamburg. Major component of psychenet was an information and awareness campaign on mental health, including mental disorders [22]. One purpose of the survey was to evaluate possible effects of the campaign in Hamburg, Munich served as control region.

The sample was comprised of adults aged 18 and older, living in private households in one of the two cities with access to conventional telephone connections. Their numbers were drawn from all registered telephone numbers at random; ex-directory households were also included via computer-generated numbers. The study was approved by the Ethics Commission of the Medical Association in Hamburg (PV3707). In total, 2,006 respondents agreed in participating; this reflects a response rate of $53 \%$. Informed consent was considered to have been given when the individuals completed the interview. Comparisons with official statistics showed that the distribution of demographic characteristics such as gender, age and education is similar to that in the general population in Hamburg and Munich [23]. In our analyses, we focus on two subsamples which had been presented either a schizophrenia $(n=1,338)$ or depression vignette $(n=1,316)$. While the case stories contained signs and symptoms suggestive of the disorders, they did not include diagnostic labels (please see annex for vignettes). The vignettes had been developed with the input of clinicians based on ICD-10 and DSM-IV criteria and audio-recorded with a trained speaker to increase reliability and to counteract possible interviewer effects. Gender of the "patient" was systematically varied. The vignette was presented in the beginning 
106 of the interview, directly followed by the question on continuum belief. Then, the interviewer

107 asked the respondents to name the disorder in the vignette. If the interviewees were not able to 108 identify the disorder correctly, they were provided with the response. Subsequently, they were 109 asked questions regarding mental health literacy (e.g. prevalence of the disorder, possible 110 treatment options) and attitudes, which are described in detail in the next section.

111 Sociodemographic characteristics of the subsamples are described in table 1.

112 Table 1 Sociodemographic characteristics of the subsamples in $\%$

\begin{tabular}{|lcc|}
\hline & $\begin{array}{c}\text { Subsample } \\
\text { schizophrenia } \\
(\mathrm{n}=1,338)\end{array}$ & $\begin{array}{c}\text { Subsample } \\
\text { depression } \\
(\mathrm{n}=1,316)\end{array}$ \\
\hline Sex (Female) & 52.3 & 51.8 \\
\hline $\begin{array}{l}\text { Level of education } \\
\text { up to 9 years }\end{array}$ & 33.4 & 31.3 \\
\hline 10 years & 23.0 & 23.9 \\
\hline $12-13$ years & 43.7 & 45.0 \\
\hline Age groups & & \\
\hline $18-25$ & 10.1 & 12.4 \\
\hline $26-45$ & 39.9 & 39.2 \\
\hline $46-65$ & 30.0 & 28.2 \\
\hline$>65$ & 20.0 & 20.2 \\
\hline Mean age (SD) & $47.7(18.1)$ & $47.2(18.3)$ \\
\hline
\end{tabular}

\section{Instruments}

114 Continuum Belief

115 Immediately following the presentation of the vignette, the interviewer posed a question on the 116 respondents' belief in a continuum of symptom experience. They were asked to indicate their 117 (dis-) agreement to the following statement: "Basically, we are all sometimes like this person. It 
118 is just a question how pronounced this state is." Answers were given on a 4-point Likert-scale

119 ranging from 1 "completely disagree" to 4 "completely agree" plus "don`t know" category.

120 Stereotypes

121 Based on previous research $[4,5]$, we chose two negative stereotypes regarding mental illness.

122 We asked respondents to what extent they would agree or disagree with the following

123 statements: "A person with [disorder in the vignette] is unpredictable" and "A person with

124 [disorder in the vignette] is dangerous" Again, answers could be given on a 4-point Likert-scale

125 (plus “don’t know” category).

126 Emotional Reactions

127 Emotional reactions were assessed by eight items representing different ways of emotionally

128 responding to the person in the vignette. Each item was coded from 1 "completely disagree" to 4

129 "completely agree". Principal component analysis yielded the same three factors also found in

130 previous research: anger, fear and prosocial reactions [24]. The items "I react angrily", "I feel

131 annoyed" and "This triggers incomprehension with me" loaded on the factor anger. The factor

132 fear was comprised of the items "This triggers fear", "I feel uncomfortable" and "I feel

133 insecure", while the items "I feel pity", "I feel sympathy", "I want to help" loaded on the factor

134 prosocial. Together, the three factors accounted for a cumulative variance of $60.3 \%$ for

135 schizophrenia and $59.1 \%$ for depression.

136 Desire for Social Distance

137 We assessed the respondents' desire for social distance by means of a scale developed by Link,

138 Cullen, Frank and Wozniak [25], a modified version of the Bogardus Social Distance Scale [26].

139 The scale includes seven items representing different social relationships, e.g. tenant, co-worker

140 or child carer. On a Likert-scale ranging from 1 "completely disagree" to 4 "completely agree",

141 the respondents were asked to indicate to what extent they would accept the person with

142 schizophrenia or depression described in the vignette. Non-linear principal component analysis

143 was carried out, all items loaded on one factor. As we have reversed the scale, higher scores

144 indicate greater desire for social distance.

145 Statistical Analyses 
146 Descriptive characteristics and bivariate associations were computed using SPSS 22 [27] (For

147 bivariate associations, please see tables in the additional material). We assessed the associations

148 between stereotypes, continuum belief, emotional reactions and desire for social distance via

149 path models computed in AMOS 22 [28]. Initially, an analysis of missing values was performed

150 and data was imputed by means of full information maximum likelihood (FIML) in AMOS [29,

151 30]. There are measures of "approximate model fit" that have been developed to avoid rejection

152 of appropriate model structures due to large sample size $(\mathrm{N}>300)$, e.g. the "root mean squared

153 error of approximation" (RMSEA). Values of $\leq 0.05$ indicate good model fit $[31,32]$.

154 Additionally, the "Tucker Lewis index" (TLI) and the "Comparative fit index" (CFI) serve as

155 indicators for good $(\geq 0.95)$ model fit [33]. We started out from a saturated model and performed

156 backward-selection of non-significant paths. The backward-selection was also applied to error

157 terms to indicate whether we can assume shared unexplained variance. The significance level is

158 set at $\alpha<0.05$; path analyses are adjusted for gender, age, level of education and identification of

159 disease.

160 Results

161 The descriptive statistics for the scales and items indicating the stigma process are summarized

162 in Table 2. Compared to depression, respondents were rather reluctant to agree with a continuity

163 of symptoms in the case of schizophrenia. Regarding emotional reactions to a person with mental

164 illness, prosocial feelings were most pronounced, followed by feelings of fear and anger, while

165 the stereotype of unpredictability was endorsed more strongly than dangerousness in both cases.

166 Regarding the results of the bivariate associations between continuum belief and stigma

167 components for both disorders, please see the tables provided as additional material.

Table 2 Distribution of social distance, emotional reactions, stereotypes and continuum belief (mean value and (standard deviation))

\begin{tabular}{|lcc|}
\hline Items & $\begin{array}{c}\text { Subsample } \\
\text { schizophrenia } \\
(\mathrm{n}=1,338)\end{array}$ & $\begin{array}{c}\text { Subsample } \\
\text { depression } \\
(\mathrm{n}=1,316)\end{array}$ \\
\hline Desire for Social Distance $^{1}$ & $19.84(4.61)$ & $15.78(4.10)$ \\
\hline $\begin{array}{l}\text { Emotional Reaction } \\
\text { Anger }\end{array}$ & $4.90(1.74)$ & $4.73(1.74)$ \\
\hline
\end{tabular}




\begin{tabular}{|llc|}
\hline Fear & $6.69(2.27)$ & $5.13(1.92)$ \\
\hline Prosocial & $8.58(1.69)$ & $8.96(1.71)$ \\
\hline $\begin{array}{l}\text { Stereotype } \\
\text { A person with [disorder in the vignette] is dangerous. }\end{array}$ & $2.47(0.82)$ & $1.83(0.82)$ \\
\hline $\begin{array}{l}\text { A person with [disorder in the vignette] is } \\
\text { unpredictable. }\end{array}$ & $3.07(0.76)$ & $2.37(0.90)$ \\
\hline Continuum Belief $^{3}$ & $2.13(0.90)$ & $2.89(0.86)$ \\
\hline
\end{tabular}

${ }^{1}$ Desire for social distance scale comprised of 7 items, ranging from $7-28 ;{ }^{2}$ Emotional reaction scales each comprised of 3 items, ranging from $3-12$; 3 Stereotypes and continuum belief ranging from 1 "completely disagree" to 4 "completely agree"

168 Table 3 displays fit measures of the path models as well as thresholds for good model fit. The $\chi^{2}-$

169 values representing goodness of fit for the models were insignificant, thus data information is

170 sufficiently explained by the models. The goodness of fit indexes displayed values of $>.95$ (TLI

171 and CFI) respectively $<.05$ (RMSEA), indicating good model fit. 
172 Table 3 Model fit

\begin{tabular}{|lccccccc|}
\hline & $\chi^{2}$ & df & $\mathrm{p}$ & $\chi^{2} / \mathrm{df}$ & $\mathrm{TLI}^{1}$ & $\mathrm{CFI}^{2}$ & RMSEA $^{3}$ \\
\hline Thresholds & & & & & & & \\
\hline For good fit & & & & $\leq 2.0$ & $\geq .95$ & $\geq .95$ & $\leq .05$ \\
\hline $\begin{array}{l}\text { Path model } \\
\text { schizophrenia }\end{array}$ & 8.30 & 6 & .217 & 1.38 & .990 & .998 & $\begin{array}{c}.017 \\
(90 \% \mathrm{CI}=.000-.042)\end{array}$ \\
\hline $\begin{array}{l}\text { Path model } \\
\text { depression }\end{array}$ & 6.75 & 7 & .456 & 0.96 & 1.00 & 1.00 & $(90 \% \mathrm{CI}=.000-.000)$ \\
\hline
\end{tabular}

${ }^{1}$ Tucker Lewis index; ${ }^{2}$ Comparative Fit index; ${ }^{3}$ Root mean squared error of approximation

173 In figure 2, the path model for schizophrenia is displayed (statistically significant paths only).

174 Contrary to what we have expected, there are no associations between the stereotypes and the

175 continuum belief. However, there are significant paths leading from the ascription of

176 "unpredictability" to the emotional responses anger and fear, as well as to desire for social

177 distance. These associations are positive, i.e. the more the respondents agree with the item

178 "unpredictable", the more they tend to react angrily or fearfully, and the greater their desire for

179 social distance. The stereotype of "dangerousness" displays similar associations with anger and

180 desire for social distance. Additionally, there is a negative association with prosocial reactions,

181 i.e. the more respondents agree with the ascription of "dangerousness" to a patient with

182 schizophrenia, the less they exhibit prosocial emotions. As expected, positive associations exist

183 between anger, fear, and desire for social distance, while prosocial reactions are negatively

184 associated with social distance. Continuum belief is associated with prosocial reactions

185 (positively) and desire for social distance (negatively). I.e. those respondents, who rather agree

186 with a continuum of symptoms, display greater prosocial emotions and less desire for social

187 distance toward a person with schizophrenia. 


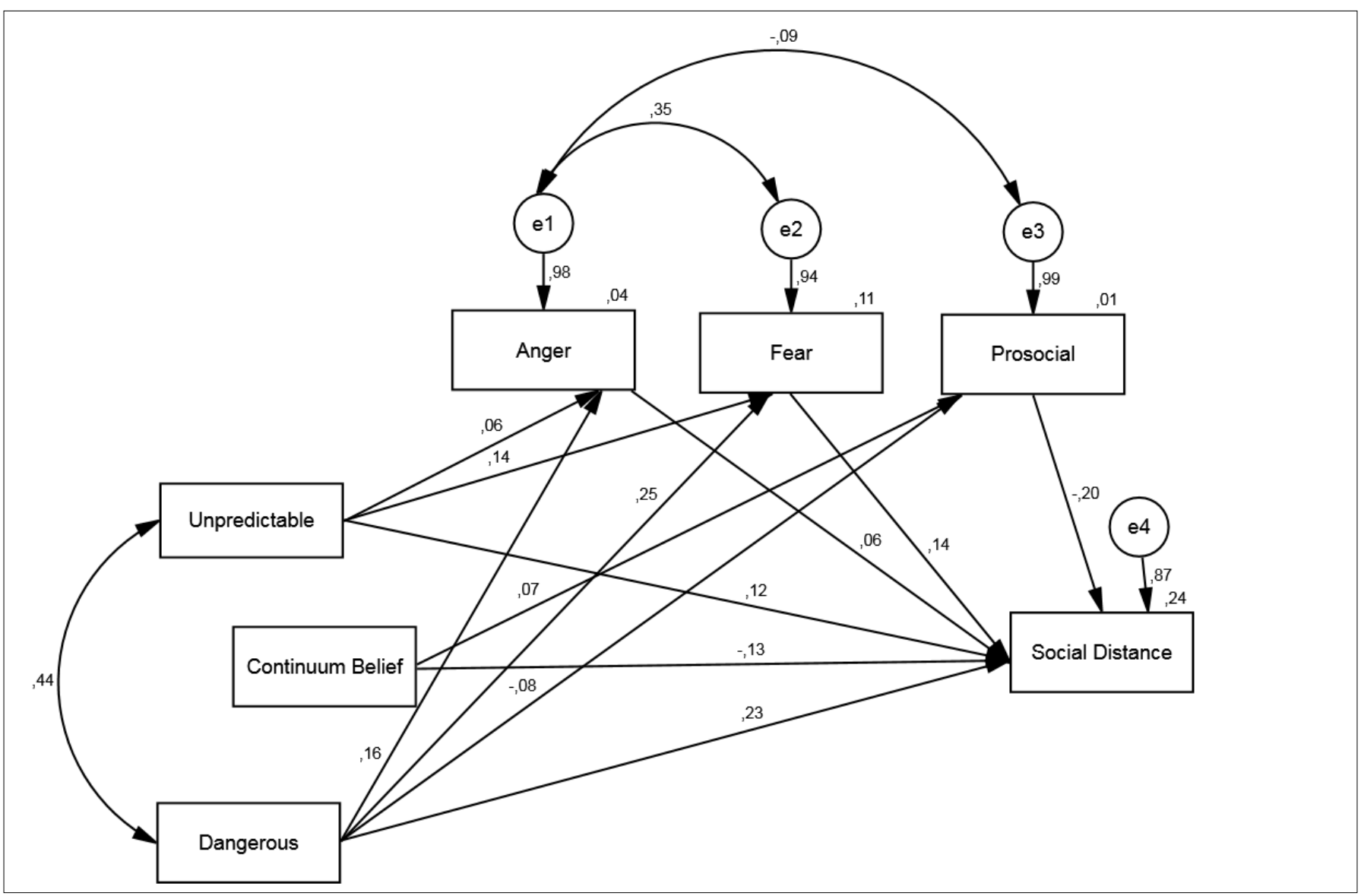

Figure 2 Schizophrenia: Path model of the relationship between stereotypes, continuum belief, emotional reactions and desire for social distance (standardized coefficients; significant paths only $(\alpha$ $<0.05)$; RMSEA: 0.017 [90\% CI 0.000; 0.042]) 
188 The path model for depression is presented in figure 3 (statistically significant paths only). As in

189 the schizophrenia-model, there are no significant paths between stereotypes and continuum

190 belief. The ascriptions of being unpredictable or dangerous are positively associated with

191 feelings of anger and fear. In contrast to the schizophrenia-model, there are no significant

192 associations between stereotypes and prosocial emotional reactions. Negative emotional

193 reactions are associated positively with desire for social distance, while the association between

194 prosocial feelings and desire for social distance is negative. As with the schizophrenia-model,

195 belief in continuity of symptoms is positively associated with prosocial reactions and negatively

196 with desire for social distance.

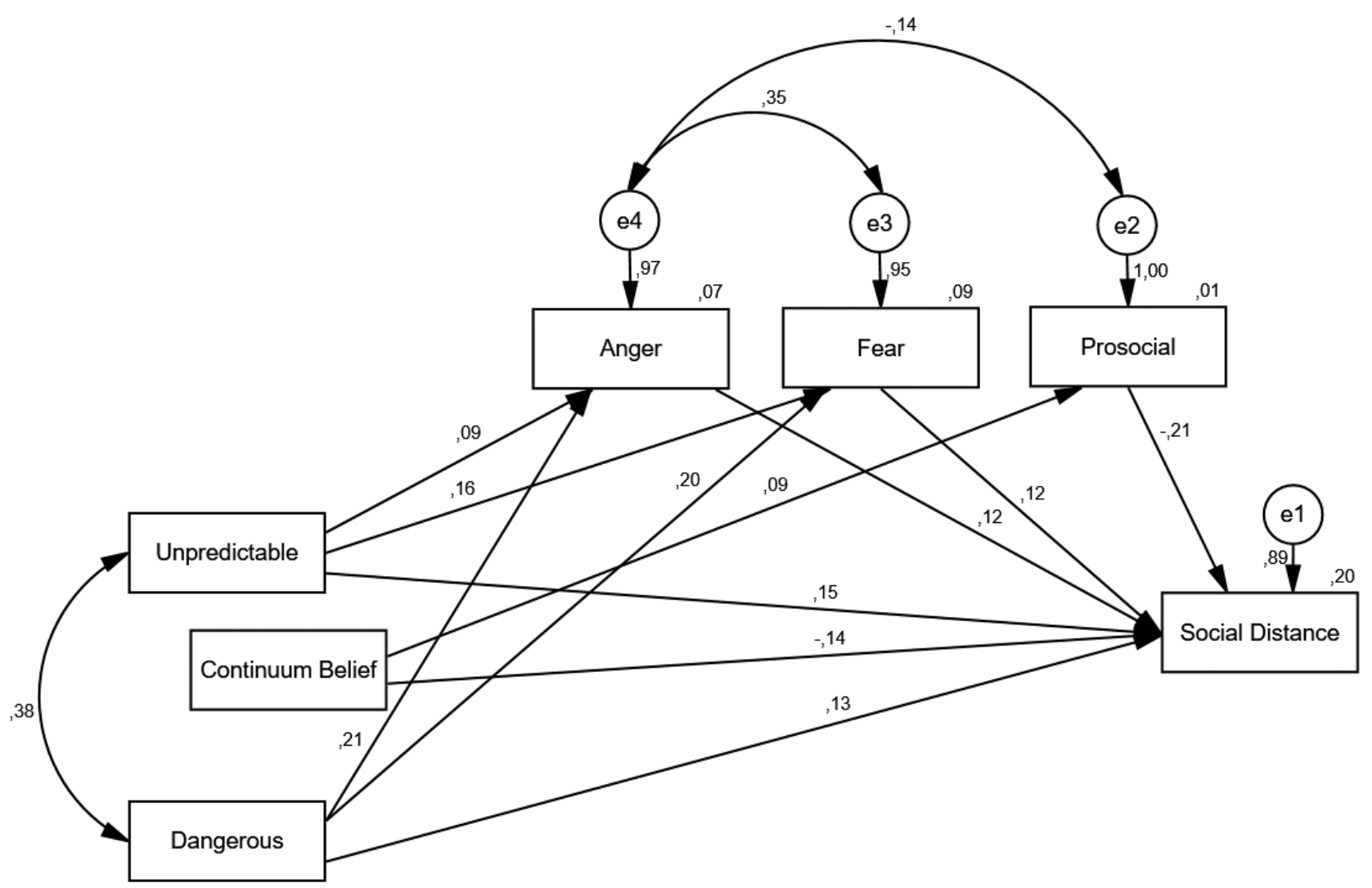

Figure 3 Depression: Path model of the relationship between stereotypes, continuum belief, emotional reactions and desire for social distance (standardized coefficients; significant paths only $(\alpha<0.05)$; RMSEA: 0.000 [90\% CI 0.000; 0.033]) 


\section{Discussion}

199 The aim of the present study was to explore associations of four consecutive components of the 200 stigma process as postulated by Link and Phelan $[11,12]$ with a particular focus on belief in 201 continuity of mental illness symptoms. The continuum belief served as a proxy for the step of 202 separation between "us" and "them" in the stigma process. We focused our analyses on the 203 stigma of persons with either schizophrenia or depression and explored associations between 204 negative stereotypes (dangerous, unpredictable), continuum belief, emotional reactions (anger, 205 fear, prosocial) and desire for social distance using a path modeling approach.

206 We expected continuum beliefs to be associated with the ascription of stereotypes as well as with 207 emotional reactions and desire for social distance (see fig. 1). However, there were no statistically significant relations between stereotypes ascribed to a person with mental illness and the belief in the continuity of symptoms. Moreover, the models revealed only two statistically significant associations regarding the continuum belief. The item was positively associated with prosocial emotional reactions and displayed a negative relation with desire for social distance. These results are in line with our expectations as well as with findings of other studies, which also showed that continuum belief was associated with more prosocial emotional reactions and less desire for social distance $[20,21]$. Contrary to what we have expected, there were no statistically significant associations between feelings of fear or anger with continuum beliefs. As far as the other hypotheses are concerned, most expectations have been met. Both stereotypes ascribed to persons with mental illness were positively associated with desire for social distance and displayed relations with emotional reactions as described in step 5 in figure 1. These results are also supported by previous research. Stereotypes have shown to have a powerful impact on the preference to socially distance oneself from a person with schizophrenia [34], and the associations between stereotypes and emotional reactions are also well researched [e.g. 15, 35 and 36]. Similarly, the positive associations between feelings of anger and fear with social

223 distance as well as a negative relation between positive emotions and preference to distance oneself have been discussed elsewhere [e.g. 37]. Regardless of the disease under study, we obtained similar results, which is remarkable and underlines the robustness of the findings. that there was an insignificant, but positive, relation between continuum beliefs and feelings of 
228 anger, which did not meet our expectations (see step 5 figure 1). This result is in line with other

229 studies $[20,21]$ and had been discussed by the authors as a negative consequence of losing the

230 sick role as established by Parsons [38]. If mental health problems are rather seen on a

231 continuum than being a dichotomy of health and illness, illness-related behavior of a person with

232 mental illness could be less accepted. However, regarding the statistical insignificance of our

233 results, we can only speculate on these associations between anger and continuum belief. The

234 paradoxical contrariety of psychiatric stigma has also been considered by Gergel [39]. On the

235 one hand, the stigma of mental illness is characterized by the idea of "otherness" caused by some

236 biological flaw. A person with mental illness is seen as intrinsically different from oneself, which

237 can facilitate negative feelings such as fear. This is referred to as unlikeness-based stigma by

238 Gergel. On the other hand, there is a second point of view on those with mental illness, which is

239 paradoxically opposed to this "otherness", termed likeness-based stigma. Assuming that a person

240 with mental illness is not inherently different from oneself, sharing similar biological and

241 environmental factors, can reinforce notions such as blame or anger, as it implies that a problem

242 or deviant behavior lies in the responsibility of the person affected and is somehow a "weakness

243 of character". At the same time, this likeness or similarity also bears the potential to elicit

244 feelings of fear or denial. Perceiving a person with mental illness as similar to oneself could be

245 met with rejection as it implicates own vulnerability. Finding a solution to this paradox still

246 represents a challenge in stigma research. A lot of research and anti-stigma work has attended to

247 the unlikeness stigma, while the likeness-based stigma is also quite prevalent. Pescosolido and

248 Martin [40] emphasize that it is important to consider different, interrelated structures when it

249 comes to understanding the complexity of stigma and its effects. In addition to that, it is of

250 importance to bear in mind the two sides of mental illness stigma when it comes to the

251 development of anti-stigma measures. Perhaps the combination of different approaches can be

252 the right means to integrate both perspectives. On the one hand, conveying knowledge about the

253 disorder. On the other hand, it has been found very important to facilitate personal contact to

254 someone affected by mental illness [41].

255 When evaluating our findings, some limitations need to be mentioned and discussed. The

256 continuum belief question was posed directly following the vignette, before respondents were

257 asked about the disorder in question. If the interviewees could not identify the disorder correctly,

258 they were given the answer by the interviewer. Thus, continuum notions evoked among 
259 respondents refer to the description of symptoms in the vignette. On the one hand, this is to 260 prefer over diagnostically labeled vignettes as these could have reinforced the notion of 261 differentness between the respondent and the person in the vignette. This might decrease the 262 belief in the continuity of symptoms. On the other hand, correct identification of the mental 263 health problem described in the vignette constitutes a possible confounder. This is why we have 264 decided to additionally control our analyses for correct identification of the disorder. It has also 265 to be kept in mind that beliefs elicited by a case vignette can be very distinct from attitudes 266 displayed when actually meeting a person with mental illness. Furthermore, we also have to 267 mention that there is a wide range of symptom presentations. Regarding the vignettes in our 268 study, we only included core diagnostic signs and symptoms to keep the case story at a 269 reasonable length. A central aspect that needs to be discussed is the absence of any statistically 270 significant associations between stereotypes and continuum belief. This led us to the question 271 whether using continuum belief as a proxy for the step of separation was the right approach.

272 However, the continuum belief fits in the conceptualization of stigma as it stresses the similarity 273 between persons with mental illness and those without, thus challenging a dichotomous view on 274 health and illness or "us" and "them". In alleviating perceived differentness between the in-group 275 and the stigmatized group, the continuum belief-item seemed the most appropriate means.

276 Moreover, the fact that we obtained similar results concerning the continuum belief, regardless

277 of the disorder under study, corroborates the robustness of the model. Nevertheless, we also have 278 to consider the fact that we only used a single item to assess agreement with the notion of 279 continuity of symptoms. This may impede a comprehensive assessment of (dis-)agreement of 280 continuity of mental illness symptoms in the public. In comparison to Wiesjahn et al. [21], we 281 only covered one possible dimension of the continuum belief. The single-item measure refers to 282 the experience of a similar situation among the "normal" population, while the questionnaire 283 used by Wiesjahn et al. [21] covered three different dimensions: prevalence of symptoms in the "normal" population, clear distinction of categories vs. continuum, as well as a dimensional approach to mental illness, symptoms and associated distress. In addition, our results are limited to two negative stereotypes (unpredictability and dangerousness). A further methodological aspect that we have to consider is the response rate. A rate of $53 \%$ is satisfactory for telephone surveys in Germany [42], however, we cannot rule out a selection bias due to non-response. At the same time, a comparison with official statistics [23] sustains the external validity of our 
290 study. It has to be kept in mind though, that our data is confined to the metropolitan regions of

291 Hamburg and Munich and of cross-sectional nature. We are aware that there can be possible

292 differences in composition of social levels and / or population age when comparing metropolitan

293 to rather rural areas in Germany. However, due to the campaign's design a certain focus on

294 Hamburg and its adjacent areas was necessary.

295 To our knowledge, this is the first study that investigated continuum beliefs in the context of the 296 stigma process approach as postulated by Link and Phelan [11, 12]. The associations found 297 support a possible destigmatizing effect of the belief in continuity of symptoms. Promulgating 298 continuum belief as a means to oppose perceived separation between "us" and "them" could 299 prove useful for future anti-stigma campaigns. This is corroborated by an experimental study by 300 Wiesjahn et al. [43], in which a continuum belief intervention was consistently associated with 301 lower stereotypes, less fear and decreased desire for social distance. Schomerus et al. [44] came 302 to similar results. In an online survey experiment, the conveyance of information on a mental 303 health-mental illness continuum led to decreased perceived difference and increased social 304 acceptance. Integrating a continuum approach into existing measures to encounter psychiatric 305 stigma would be feasible, e.g. when it comes to work in small to medium sized groups where 306 dissemination of knowledge is combined with personal contact to someone with mental illness, a 307 form of intervention that has been shown to have great effects on stigmatizing attitudes [41]. 


\section{Acknowledgements}

309 psychenet is a project network in the region of Hamburg which consists of more than 80

310 scientific and medical institutions, counselling centers, the Senate and the Chamber of

311 Commerce of the Free and Hanseatic City of Hamburg, companies, as well as patients' and

312 relatives' associations $(2011-2015)$. The vision of the project is to promote mental health today

313 and in the future, concerning early diagnosis and effective treatment of mental illnesses.

314 Coordination of the joint project is mutually carried out by the Gesundheitswirtschaft Hamburg

$315 \mathrm{GmbH}$ and the University Medical Center Hamburg-Eppendorf. For more information and a list 316 of all partners please visit www.psychenet.de. 


\section{References}

318 [1] Alonso J, Buron A, Rojas-Farreras S, de Graaf R, Haro JM, de Girolamo G, Bruffaerts R, 319 Kovess V, Matschinger H, Vilagut G, for the ESEMeD/MHEDEA 2000 Investigators. 2009.

320 Perceived stigma among individuals with common mental disorders. Journal of Affective

321 Disorders 118:180-186

322 [2] Livingston JD, Boyd JE. 2010. Correlates and consequences of internalized stigma for people 323 living with mental illness: A systematic review and meta-analysis. Social Science and Medicine,

$324 \quad 71: 2150-2161$

325 [3] Angermeyer MC, Matschinger H, Carta MG, Schomerus G. 2014. Changes in the perception 326 of mental illness stigma in Germany over the last two decades. European Psychiatry 29 (6):390327395

328 [4] Angermeyer MC, Matschinger H. 2004. The stereotype of schizophrenia and its impact on 329 discrimination against people with schizophrenia: Results from a representative survey in 330 Germany. Schizophrenia Bulletin 30(4):1049-1061

331 [5] Thonon B, Pletinx A, Grandjean A, Billieux J, Larøi F. 2016. The effects of a documentary 332 film about schizophrenia on cognitive, affective and behavioural aspects of stigmatisation. 333 Journal of Behavior Therapy and Experimental Psychiatry 50:196-200

334 [6] Jorm AF, Christensen H, Griffiths KM (2005) The impact of beyondblue: the national 335 depression initiative on the Australian public's recognition of depression and beliefs about 336 treatments. Australian and New Zealand Journal of Psychiatry 39:248-254

337 [7] Evans-Lacko S, Henderson C, Thornicroft G (2013) Public knowledge, attitudes and 338 behavior regarding people with mental illness in England 2009-2012. British Journal of 339 Psychiatry $202(55):$ s51-7

340 [8] Hegerl U, Althaus D, Stefanek J (2003) Public attitudes towards treatment of depression: 341 Effects of an information campaign. Pharmacopsychiatry 36 (6):288-291

342 [9] Makowski AC, Mnich EE, Ludwig J, Daubmann A, Bock T, Lambert M, Härter M, Dirmaier 343 J, Tlach L, Liebherz S, von dem Knesebeck O (2016) Changes in beliefs and attitudes toward 344 people with depression and schizophrenia - results of a public campaign in Germany. Psychiatry 345 Research 237:271-278

346 [10] Grausgruber A, Schöny W, Grausgruber-Berner R, Koren G, Frajo Apor B, Wancata J, 347 Meise U (2009) "Schizophrenie hat viele Gesichter" - Evaluation der österreichischen Anti348 Stigma-Kampagne [,,Schizophrenia has Many Faces” - Evaluation of the Austrian Anti-Sigma349 Campaign 2000-2002]. Psychiatrische Praxis 36:327-333

350 [11] Link BG, Phelan JC. 2001. Conceptualizing stigma. Annual Review of Sociology 27:363351385

352 [12] Link BG, Yang LH, Phelan JC, Collins PY. 2004. Measuring mental illness stigma. 353 Schizophrenia Bulletin 30(3):511-541 
354 [13] Weiner B. 1985. An attributional theory of achievement motivation and emotion.

355 Psychological Review 92(4):548-573

356 [14] Angermeyer MC, Matschinger H. 2005. Labeling - stereotype - discrimination: An investigation of the stigma process. Social Psychiatry and Psychiatric Epidemiology 40:391-395

358

359

360

361

362

363

364

365

366

367

368

369

370

371

372

373

374

375

376

377

378

379

380

381

382

383

384

385

386

387

388

389

390

391

392

[15] Angermeyer MC, Matschinger H. 2003. The stigma of mental illness: effects of labelling on public attitudes towards people with mental disorder. Acta Psychiatrica Scandinavica 108(4): 304-309

[16] Martin JK, Pescosolido BA, Tuch SA. 2000. Of fear and loathing: the role of 'disturbing behavior' in shaping public attitudes labels and causal attributions toward people with mental illness. Journal of Health and Social Behavior, 41(2):208-223

[17] Read J, Haslam N, Sayce L, Davies E. 2006. Prejudice and schizophrenia: a review of the "mental illness is an illness like any other" approach. Acta Psychiatrica Scandinavica 114:303318

[18] Jorm AF, Griffiths KM. 2008. The public's stigmatizing attitudes towards people with mental disorders: how important are biomedical conceptualizations? Acta Psychiatrica

Scandinavica 118:315-321

[19] Schomerus G, Matschinger H, Angermeyer MC. 2013. Continuum beliefs and stigmatizing attitudes towards persons with schizophrenia, depression and alcohol dependence. Psychiatry Research 209(3):665-669

[20] Angermeyer MC, Millier A, Remuzat C, Refai T, Schomerus G, Toumi M. 2014.

Continuum beliefs and attitudes towards people with mental illness: Results from a national survey in France. International Journal of Social Psychiatry doi: 10.1177/0020764014543312

[21] Wiesjahn M, Brabban A, Jung E, Gebauer UB, Lincoln TM. 2014. Are continuum beliefs about psychotic symptoms associated with stereotypes about schizophrenia? Psychosis 6(1):5060

[22] Härter M, Kentgens M, Brandes A, Bock T, Dirmaier J, Erzberger M, Fürstenberg W, Hillebrandt B, Karow A, Knesebeck Ovd, König HH, Löwe B, Meyer HJ, Romer G, Rouhiainen T, Scherer M, Thomasius R, Watzke B, Wegscheider K, Lambert M. 2012. Rationale and content of psychenet: the Hamburg Network for Mental Health. European Archives of Psychiatry and Clinical Neuroscience 262:57-63

[23] Mnich EE, Makowski AC, Kofahl C, Lambert M, Bock T, Angermeyer MC, Knesebeck Ovd. 2015. Was weiß und denkt die Bevölkerung über psychische Erkrankungen?

Ergebnisevaluation der psychenet-Aufklärungskampagne [What does the public know and think about mental disorders? Evaluation of the awareness campaign "psychenet"]. Psychiatrische Praxis 42(S01):S20-S24

[24] Angermeyer MC, Holzinger A, Matschinger H. 2010. Emotional reactions to people with mental illness. Epidemiologica e Psichiatria Sociale 19:26-32

[25] Link BG, Cullen FT, Frank J, Wozniak JF. 1987. The social rejection of former mental patients: understanding why labels matter. American Journal of Sociology 92(6):1461-1500 
393 [26] Bogardus ES. 1925. Measuring social distance. Journal of Applied Sociology 9:299-308

394 [27] IBM Corp. Released 2013. IBM SPSS Statistics for Windows, Version 22.0. Armonk, NY, 395 IBM Corp.

396 [28] Arbuckle JL. 2013. Amos (Version 22.0) [Computer Program]. Chicago: SPSS

397 [29] Arbuckle JL. 1996. Full information estimation in the presence of incomplete data. In:

398 Marcoulides GA \& Schumacker RE, eds. Advanced structural equation modeling. Mahwah, NJ:

399 Lawrence Erlbaum Associates Inc., 243-277.

400 [30] Enders CK, Bandalos DL. 2001. The relative performance of Full Information Maximum

401 Likelihood estimation for missing data in structural equation models. Structural Equation

402 Modeling 8(3):430-457

403 [31] Browne MW, Cudeck R. 1993. Alternative ways of assessing model fit. In: Bollen KA \&

404 Long JS, eds. Testing structural equation models. Newbury Park, CA: Sage, 136-162.

405 [32] Steiger JH. 1990. Structural model evaluation and modification: An interval estimation 406 approach. Multivariate Behavioral Research 25:173-180

407 [33] Hu L, Bentler PM. 1999. Cutoff criteria for fit indexes in covariance structure analysis:

408 Conventional criteria versus new alternatives. Structural Equation Modeling 6(1):1-55

409 [34] Angermeyer MC, Matschinger H. 2004. The stereotype of schizophrenia and its impact on 410 discrimination against people with schizophrenia: results from a representative survey in

411 Germany. Schizophrenia Bulletin 30(4):1049-1061

412 [35] Corrigan PC, Rowan D, Qreen A, Lundin R, River P, Uphoff-Wasowski K, White K, 413 Kubiak MA. 2002. Challenging Two Mental Illness Stigmas: Personal Responsibility and 414 Dangerousness. Schizophrenia Bull 28(2):293-309

415 [36] Angermeyer MC, Dietrich S. 2006. Public beliefs about and attitudes towards people with 416 mental illness: a review of population studies. Acta Psychiatrica Scandinavica 113:163-179

417 [37] von dem Knesebeck O, Angermeyer MC, Kofahl C, Makowski AC, Mnich E. 2014.

418 Education and the public's desire for social distance from people with depression and 419 schizophrenia: the contribution of emotional reactions and causal attributions. International 420 Journal of Social Psychiatry 60(5):468-473

421 [38] Parsons T. 1951. Illness and the role of the physician: A sociological perspective. American 422 Journal of Orthopsychiatry 21:452-460

423 [39] Gergel TL. 2014. Too similar, too different: the paradoxical dualism of psychiatric stigma.

424 Psychiatric Bulletin 38:148-151

425 [40] Pecosolido BA, Martin JK. 2015. The stigma complex. Annual Review of Sociology 41: 87426116

427 [41] Griffiths KM, Carron-Arthur B, Parsons A, Reid R. 2014. Effectiveness of programs for 428 reducing the stigma associated with mental disorders. A meta-analysis of randomized controlled 429 trials. World Psychiatry 13:161-175 
430 [42] Schlinzig T, Schneiderat G. 2009. Möglichkeiten zur Erhöhung der Teilnahmebereitschaft 431 bei Telefonumfragen über Festnetz und Mobilfunk. [How to increase response rates in telephone 432 surveys.] In: Weichbold M, Bacher J, Wolf C (eds) Umfrageforschung. Herausforderungen und 433 Grenzen. [Survey research. Challenges and limits], VS, Wiesbaden, pp 21-43

434 [43] Wiesjahn M, Jung E, Kremser JD, Rief W, Lincoln TM. 2015. The potential of continuum 435 versus biogenetic beliefs in reducing stigmatization against persons with schizophrenia: An 436 experimental study. Journal of Behavioral Therapy and Experimental Psychiatry 50:213-237

437 [44] Schomerus G, Angermeyer MC, Baumeister SE, Stolzenburg S, Link BG, Phelan JC. 2016. 438 An online intervention using information on the mental health-mental illness continuum to 439 reduce stigma. European Psychiatry 32: 21-27 


\section{Appendix: Vignettes}

440 Schizophrenia*:

441 For around half a year now, 19-year-old Sabine S. retreats more and more in herself, avoids all 442 contacts and has the impression that other people can read her mind. She is often scatterbrained 443 and absent-minded. For some time now, Sabine has been feeling threatened and persecuted. She 444 also hears voices which disrupt her thoughts and give her instructions.

445 Depression*:

446 46-year-old Dagmar D. has been constantly downhearted and unhappy for the last few months.

447 She worries about the future. Mrs. D. feels useless, has the impression everything she does is

448 wrong and has lost all interest in everyday activities. Besides, she complains about insomnia and

449 feels nerveless and weak, already in the mornings. Mrs. D's capability to work turns out to be 450 declining.

$451 *$ Gender of the "patient" was systematically varied. 